\title{
Is encopresis always the result of constipation?
}

\author{
M A Benninga, H A Büller, H S A Heymans, G N J Tytgat, J A J M Taminiau
}

\begin{abstract}
Encopresis is often the result of chronic constipation in the majority of paediatric patients. In clinical practice, however, encopresis is also seen without constipation and it is unknown whether these two clinical variants are based on similar or different pathophysiological mechanisms, requiring different therapeutic approaches. We analysed clinical symptoms, colonic transit time (CTT), orocaecal transit time (OCTT), anorectal manometric profiles, and behavioural scores. Patients were divided into two groups, one consisted of 111 children with paediatric constipation, and another group of 50 children with encopresis and/or soiling without constipation.
\end{abstract}

Significant clinical differences in children with encopresis/soiling existed compared with children with paediatric constipation regarding: bowel movements per week, the number of daytime soiling episodes, the presence of night time soiling, the presence and number of encopresis episodes, normal stools, pain during defecation, abdominal pain, and good appetite.

Total and segmental CTT were significantly prolonged in paediatric constipation compared with encopresis/soiling, 62.4 (3.6-384) and 40.2 (10.8-104.4) hours, respectively. No significant differences were found in OCTT. Among the two groups, all manometric parameters were comparable, except for a significantly higher threshold of sensation in children with paediatric constipation. The defecation dynamics were abnormal in $59 \%$ and $46 \%$ in paediatric constipation and encopresis/soiling, respectively, and were significantly different from controls. Using the child behaviour checklist no significant differences were found when comparing children with paediatric constipation and encopresis/soiling, while both patient groups differed significantly from controls.

In conclusion, our findings support the concept of the existence of encopresis as a distinct entity in children with defecation disorders. Identification of such children is based on clinical symptoms, that is, normal defecation frequency, absence of abdominal or rectal palpable mass, in combination with normal marker studies and normal anal manometric threshold of sensation. Thus, encopresis is not always the result of constipation and can be the only clinical presentation of a defecation disorder.

(Arch Dis Child 1994; 71: 186-193)

Children with faecal incontinence are not capable of controlling their bowels. Many doctors regard it as a trivial symptom which will eventually disappear. Apart from the shame and fear of discovery, however, it may lead to social withdrawal, low self esteem, and depression. ${ }^{1-3}$ Despite these consequences in children, encopresis and soiling have received less attention than enuresis.

The term encopresis was originally introduced by Weissenberg in 1926 to characterise the faecal equivalent of enuresis. ${ }^{4}$ Many have tried to define and classify encopresis, but no agreement has been reached. Some workers divide encopresis into either faecal incontinence with evidence of constipation (psychogenic constipation, psychogenic megacolon, paradox diarrhoea, or overflow incontinence), ${ }^{5-8}$ so called retentive encopresis, or non-retentive encopresis. The latter is further subdivided into a primary (or continuous) form (faecal incontinence with no evidence of constipation occurring in children who have not been toilet trained successfully) and secondary (or discontinuous) non-retentive encopresis (occurring in children who were completely toilet trained and subsequently regressed to incontinence).${ }^{9-11}$ In contrast, however, Levine stated that virtually all children with encopresis retain stools. ${ }^{1} \mathrm{He}$ suggested that a plain radiograph of the abdomen often exposed substantial faecal retention, despite a normal history and physical examination. He therefore considered the term 'encopresis without constipation' to be incorrect.

The term faecal incontinence encompasses encopresis and soiling. The important difference is the amount of faeces lost. These two terms are often used indistinguishably in published work. In this study we define encopresis as the voluntary or involuntary passage of a normal bowel movement in the underwear (or other unorthodox locations), after the age of 4 years, occurring on a regular basis without any organic cause. 51213 Thus encopresis is defined on the basis of a sign, rather than the presence or absence of 
constipation, and reflects defecation in the underwear. Faecal soiling is defined as the involuntary seepage of faeces which is often associated with faecal impaction, and reflects staining of the underwear. ${ }^{6712}$

Encopresis is reported to be responsible for $3 \%$ of referrals to teaching hospitals and has been noted in $1.3 \%$ of those over 4 and in $1-2 \%$ of 7 year olds. ${ }^{513} 14-16$ The prevalence among children of $10-12$ years was $1 \cdot 3 \%$ for boys and $0.3 \%$ for girls. ${ }^{5}$

Although faecal incontinence is a common problem in paediatric practice, the pathophysiological mechanisms are largely unknown. Marker studies have shown that the total colonic transit time (CTT) in constipated children is significantly prolonged compared with healthy controls. ${ }^{17-19}$ Anorectal manometry in children with constipation and encopresis showed an increased threshold to perceive rectal distention and an inability to relax the external anal sphincter during defecation. ${ }^{20-23}$

To find out whether faecal incontinence exists in the absence of constipation and to unravel possible different pathophysiological mechanisms, we analysed children with constipation with or without encopresis/soiling and children with encopresis/soiling only. Differences among these patients regarding their clinical symptoms, CTT, orocaecal transit time (OCTT), anorectal manometric profiles, and scores on the child behaviour checklist (CBCL) were evaluated.

\section{Methods}

SUBJECTS

In this study, 161 otherwise healthy patients with defecation disorders, aged 5-17 years, were referred between 1991 and 1993 to our paediatric intestinal motility unit of a tertiary academic teaching hospital. Patients were referred by general practitioners, school doctors, paediatricians, or child psychiatrists. Patients had to fulfil at least two of our four criteria of paediatric constipation to participate in the study: (a) stool frequency less than three each week; (b) two or more soiling/encopresis episodes each week; (c) periodic passage of large amounts of stool at least once every seven to 30 days; and (d) a palpable abdominal or rectal mass. In addition, all patients were enrolled with two or more episodes each week of encopresis or soiling alone without any of the other criteria for paediatric constipation. A palpable rectal mass was defined as the presence of a faecal lump in the rectal ampulla. Known causes of constipation, such as Hirschsprung's disease, spina bifida occulta, hypothyroidism or other metabolic or renal abnormalities, mental retardation, and children receiving drugs other than laxatives were excluded.

Each child underwent a complete work up that encompassed a detailed medical history and a thorough physical and digital rectal examination. Specific attention was paid to defecation frequency on the toilet, questions about the amount of stools lost in the underwear (encopresis, soiling), and time of occurrence. In addition, transit time studies and anorectal manometry were performed and the CBCL was completed. The study was approved by the hospital's medical ethics committee. Written informed consent was obtained from patients or their parents, or both.

Healthy controls for the OCTT test and for the anorectal manometry were 39 and 15 healthy children, respectively. Informed consent was obtained from the subjects and their parents.

\section{ASSESSMENT OF OCTT AND CTT}

Because of poor compliance in children regarding the intake of alimentary fibre, no standardisation was attempted and measurement of OCTT and CTT were performed in patients taking their own customary diet. Treatment with laxatives (pills or enemas) was always interrupted at least four days before the study. No subject had received antibiotics for at least three months before the test. ${ }^{24}$

\section{COLONIC TRANSIT TIME}

Total and segmental analysis of CCTs were carried out as reported previously. ${ }^{25}$ Patients ingested a capsule with 20 radio-opaque markers on three consecutive days at 9.00 am. Abdominal radiographs were obtained on the same time in the morning on day 1 and four days after ingestion of the last capsule. Additional abdominal radiographs were taken seven, 10, and 13 days after ingestion of the last capsule if more than $20 \%$ of markers were still present. Abdominal radiographs were obtained using a high kilovoltage fast film technique to reduce radiation exposure (estimated surface exposure $0.08 \mathrm{mrad}$ per film).

Localisation of markers on abdominal films relied on the identification of bony landmarks as described by Arhan et al. ${ }^{26}$ Markers were counted in the right, left, and rectosigmoid regions, and mean segmental transit times were calculated as described. ${ }^{25} 26$ The normal range for segmental transit times were taken from the limits (mean (2 SD)) from a study of Arhan $e t$ al in healthy children. ${ }^{26}$

\section{OROCAECAL TRANSIT TIME}

The method used to study OCTT was as described by van der Kley-van Moorsel et al. ${ }^{27}$ Studies were performed after an overnight fast. End expiratory breath samples were taken before the ingestion of $10 \mathrm{~g}$ lactulose $(20 \mathrm{ml}$ of $50 \%$ solution) and at 15 minute intervals thereafter up to a maximum of 240 minutes. ${ }^{28}$ At all time points, measurements consisted of two samples taken one minute apart. The breath was collected in a $60 \mathrm{ml}$ plastic syringe with a side hole and a mouthpiece at the tip opening. ${ }^{27}$ The hydrogen content of the expelled air was measured by the Hoekloos Lactoscreen $^{27}$ and expressed in parts per million (ppm). The OCTT was defined as the 
Table 1 Clinical features of groups defined by symptoms. The entries are number (\%) or median (range)

\begin{tabular}{|c|c|c|c|}
\hline & $\begin{array}{l}\text { Paediatric constipation } \\
(n=111)\end{array}$ & $\begin{array}{l}\text { Encopresis/soiling } \\
(n=50)\end{array}$ & p Value \\
\hline $\begin{array}{l}\text { Boys } \\
\text { Age }\end{array}$ & $\begin{array}{l}75(68) \\
8 \cdot 0(5-14)\end{array}$ & $\begin{array}{l}43(86) \\
9 \cdot 0(5-17)\end{array}$ & $\begin{array}{l}0 \cdot 02 \\
0 \cdot 01\end{array}$ \\
\hline \multicolumn{4}{|l|}{ Age of onset of symptoms (months) } \\
\hline$<12$ & $\begin{array}{l}28(25) \\
52(47)\end{array}$ & & \\
\hline Toilet trained & $61(56)$ & $34(69)$ & $0 \cdot 12$ \\
\hline Age at which toilet training started (years) & $1 \cdot 5(0 \cdot 8-4)$ & $2 \cdot 0(1-4)$ & 0.02 \\
\hline Primary encopresis & $27(25)$ & $23(47)$ & 0.02 \\
\hline Family history of constipation & $42(38)$ & $15(30)$ & $0 \cdot 38$ \\
\hline Bowel movements/week & $2 \cdot 0(0-10)$ & $7 \cdot 0(3-17)$ & $<0.01$ \\
\hline Large amount of stools (7-30 days) & $68(61)$ & $0(0)$ & $<0 \cdot 01$ \\
\hline Daytime soiling & $86(77)$ & $34(68)$ & 0.33 \\
\hline Episodes/week & $7 \cdot 0(0-56)$ & $3.5(0-28)$ & 0.03 \\
\hline Night time soiling & $33(30)$ & $6(12)$ & 0.02 \\
\hline Episodes/week & $0(0-7)$ & $0(0-10)$ & 0.02 \\
\hline Encopresis & $36(32)$ & $33(66)$ & $<0 \cdot 01$ \\
\hline Episodes/week & $0(0-35)$ & $3 \cdot 0(0-28)$ & $<0.01$ \\
\hline Normal stools (consistency) & $60(54)$ & $41(82)$ & 0.03 \\
\hline Pain during defecation & $55(50)$ & $15(30)$ & 0.03 \\
\hline No rectal sensation & $20(18)$ & $3(6)$ & 0.05 \\
\hline Abdominal pain & $46(41)$ & $11(22)$ & 0.02 \\
\hline Good appetite & $64(58)$ & $39(78)$ & 0.01 \\
\hline Daytime urinary incontinence & $12(11)$ & $7(14)$ & 0.37 \\
\hline Night time urinary incontinence & $29(26)$ & $10(20)$ & 0.43 \\
\hline Palpable abdominal mass & $39(35)$ & $0(0)$ & $<0.01$ \\
\hline Palpable rectal mass & $31(28)$ & $0(0)$ & $<0.01$ \\
\hline
\end{tabular}

period between lactulose intake by mouth and an increase in hydrogen excretion of $10 \mathrm{ppm}$ above basal values. The test was terminated when this increase in hydrogen excretion sustained two subsequent time intervals. Nonhydrogen producers were defined as children with a peak excess breath hydrogen concentration $<10 \mathrm{ppm}$ after lactulose ingestion.

\section{ANORECTAL MANOMETRY}

A five lumen manometric anal probe of 4.8 $\mathrm{mm}$ outer and $0.8 \mathrm{~mm}$ inner diameter was used as described earlier. ${ }^{29}$ Two side holes at a spacing of $3 \mathrm{~cm}$ were perfused with sterile water at a rate of $0.5 \mathrm{ml} / \mathrm{min}$ by a hydraulic infusion system (Arndorfer). ${ }^{30} \mathrm{~A}$ rectal distending balloon with a high compliance was tied to the tip of the probe, $3 \mathrm{~cm}$ above the first side hole. Pressures were measured by transducers in each perfusion line and connected to PC Polygraf HR preamplifiers (Synectics Medical). The analogue signals from the preamplifier were digitally converted and transmitted via a fibre optic cable to a personal computer.

Maximum anal resting tone and maximum squeeze pressure were measured by stationary pull through at a rate of $1 \mathrm{~cm} / \mathrm{min}$. Sensory threshold was defined by the smallest reproducible volume of rectal distension sensed. Critical volume, the minimum amount of air required to produce the sensation of a persistent urge to defecate (for at least one minute), was determined by filling the rectal balloon stepwise in increments of $30 \mathrm{ml}$ at intervals of 30 seconds. Intra-abdominal pressure was defined as the increase of pressure above the steady state level during a defecation attempt. The defecation dynamics, the manometric profile obtained by expelling the rectal balloon, was assessed during at least five simulated defecation trials. The rectoanal inhibitory reflex was measured in response to balloon distension to exclude (short segment) Hirschsprung's disease. No sedation was used.

\section{ELECTROMYOGRAPHY}

Electrical activity of the external anal sphincter was recorded by one reference and two differential electrodes connected to a bioamplifier II and the PC Polygraf HR. Electrocardiogram pregelled disposable neonatal electrodes overlaying the subcutaneous part of the external anal sphincter were used. The reference electrode was located on a thigh. Defecation dynamics were defined as normal if the integrated electromyogram of the external anal sphincter showed a decrease or no change during expulsion of the balloon in at least two of five defecation attempts. Defecation dynamics were defined as abnormal if a manometric and myoelectrical increase occurred during bearing down in at least four of the five defecation attempts. ${ }^{22} 3132$

\section{CHILD BEHAVIOUR CHECKLIST}

The CBCL is a questionnaire developed by Achenbach and is designed to report in a standardised way the behaviour of children aged 4 to 16 years as assessed by their parents or parent proxy. ${ }^{33}$ The CBCL was completed within 14 days after the initial visit. Normalised $T$ scores for the social competence scale, the internalisation score, the externalisation score, and the total behavioural score are standardised for age and gender. ${ }^{34}$ The behavioural ratings were compared with the behavioural ratings of the CBCL normative sample of non-referred Dutch children $(n=2076)$, all of whom are profiled by age and gender. ${ }^{34}$

\section{STATISTICAL METHODS}

Data were collected using an integrated patient database. Results will be expressed using the median and the range for continuous variables and percentages for discrete variables. Groups were compared using the Wilcoxon paired signed rank test for continuous variables and the $\chi^{2}$ test for discrete variables, calculating exact $p$ values for the latter. For all tests a level of 0.05 was used for significance.

\section{Results}

PATIENTS

This study encompasses 161 patients evaluated for constipation or encopresis/soiling, or both. Based on our definition of paediatric constipation, patients were divided into two groups. The first group consisted of 111 patients who fulfilled the criteria for paediatric constipation as described earlier. The second group consisted of 50 patients with encopresis or soiling alone, or both, without other criteria of paediatric constipation.

In 39 healthy children (5-14 years, average 9.9 years; 18 boys and 21 girls) breath hydrogen samples were taken to obtain normal OCTTs. Controls for the manometric values consisted of 15 healthy children (7-15 years, average 11 years; 10 boys and five girls).

Apart from a significant preponderance of boys in the encopresis/soiling group, children 
Table 2 CTT in hours (mean and range)

\begin{tabular}{|c|c|c|c|}
\hline & $\begin{array}{l}\text { Paediatric constipation } \\
(n=111)\end{array}$ & $\begin{array}{l}\text { Encopresis/soiling } \\
(n=50)\end{array}$ & $\begin{array}{l}\text { Arhan } \\
(n=23)\end{array}$ \\
\hline $\begin{array}{l}\text { Right colon } \\
\text { Left colon } \\
\text { Rectosigmoid } \\
\text { Total colon }\end{array}$ & $\begin{array}{l}13.8(0-60)(p<0.01) \\
16.1(0-110.4)(p<0.01) \\
51.0(0-226.8)(p<0.01) \\
81.0(3.6-380.4)(p<0.01)\end{array}$ & $\begin{array}{c}8 \cdot 1(0-26 \cdot 4) \\
7 \cdot 0(0-19 \cdot 2) \\
26 \cdot 7(4 \cdot 8-93 \cdot 6) \\
41 \cdot 7(10 \cdot 8-104 \cdot 4)\end{array}$ & $\begin{array}{r}7 \cdot 7(18) \\
8 \cdot 7(20) \\
12 \cdot 4(34) \\
29 \cdot 0(62)\end{array}$ \\
\hline
\end{tabular}

*The last column represents the mean values; the values in brackets are upper limits of normal range (mean ( $2 \mathrm{SD})$ ) measured by Arhan et al. ${ }^{26}$

with encopresis/soiling were significantly older than the patients with paediatric constipation (table 1). The age at which parents first remembered a bowel problem in the paediatric constipation group was, in most children, between 12 and 48 months. In the 27 children with secondary encopresis, bowel problems started at a median age of 6 years (2-10 years). The remaining 23 children of the encopresis/soiling group were never continent for faeces (primary encopresis). The median duration of constipation was 60 months in the paediatric constipation group (2-171 months). In the encopresis/soiling group the median period of the disorder was 10 years (5-14) and 50 months (3-137) for primary and secondary encopresis/soiling respectively.

\section{ONSET OF CONSTIPATION}

As mentioned by the parents, no definable events were present at the onset of constipation in most paediatric constipation and encopresis/soiling children $(68 \%$ and $78 \%$ respectively). Definable events such as diet changes (human to cows' milk), anal fissures, failed toileting, birth of a sibling, family problems, moving to a new home, changing school, intercurrent illness, or sexual abuse were present at onset in a minority of cases (maximum $8 \%$ ).

BOWEL FUNCTION

As shown in table 1 , the median number of bowel movements in the paediatric constipation group was two times each week, whereas the encopresis/soiling patients defecated on the toilet daily. As reported by the encopresis/soiling patients or their parents, or both, the stools were of normal size, without a periodic passage of a large amount of stools.

The number of day or night time, or both, soiling episodes was significantly higher in the paediatric constipation group compared with the encopresis/soiling group. The presence and number of episodes of encopresis was

Table 3 Results of anorectal manometry (median and range)

\begin{tabular}{|c|c|c|c|}
\hline & $\begin{array}{l}\text { Paediatric } \\
\text { constipation } \\
(n=111)\end{array}$ & $\begin{array}{l}\text { Encopresis/soiling } \\
(n=50)\end{array}$ & $\begin{array}{l}\text { Healthy controls } \\
(n=15)\end{array}$ \\
\hline $\begin{array}{l}\text { Maximum anal resting tone }(\mathrm{mm} \mathrm{Hg}) \\
\text { Maximum squeeze pressure }(\mathrm{mm} \mathrm{Hg}) \\
\text { Abdominal resting pressure }(\mathrm{mm} \mathrm{Hg}) \\
\text { Intra-abdominal pressure }(\mathrm{mm} \mathrm{Hg}) \\
\text { Threshold of sensation }(\mathrm{ml}) \\
\text { Threshold of reflex }(\mathrm{ml}) \\
\text { Critical volume (ml) } \\
\text { Defecation dynamics (normal) }\end{array}$ & $\begin{array}{l}56 \cdot 0(27-93) \\
138 \cdot 0(65-288) \\
10 \cdot 0(1-35) \\
67 \cdot 0(16-151) \\
25 \cdot 0(5-360)^{\star} t \\
27 \cdot 5(5-60)^{\star} \\
150 \cdot 0(60-360) \\
41 \% \star\end{array}$ & $\begin{array}{c}63 \cdot 5(18-95)^{\star} \\
140 \cdot 5(62-264) \\
8 \cdot 5(1-34) \\
64 \cdot 0(0-180) \\
15 \cdot 0(10-90) \\
25 \cdot 0(10-60)^{\star} \\
120 \cdot 0(60-330) \\
54 \%^{\star}\end{array}$ & $\begin{array}{l}46 \cdot 0(33-90) \\
167 \cdot 0(81-276) \\
10 \cdot 0(4-18) \\
65 \cdot 0(32-131) \\
20 \cdot 0(5-50) \\
17 \cdot 5(5-40) \\
120 \cdot 0(60-180) \\
93 \%\end{array}$ \\
\hline
\end{tabular}

*Statistically significant from controls. †Statistically significant from encopresis/soiling group. significantly more common in the encopresis/ soiling group. In the paediatric constipation group $13 \%$ of the children, six boys $(8 \%)$ and seven girls (19\%), did not have faecal incontinence.

\section{ASSOCIATED SYMPTOMS}

A large number of children with paediatric constipation experienced abdominal pain, although this was only found in a minority of encopresis/soiling children. A significantly higher proportion of encopresis/soiling patients had a good appetite compared with the paediatric constipation patients. There was no significant difference in frequency between the two groups regarding day or night, or both, urinary incontinence. The existence of urinary tract infection was not evaluated in this study.

\section{ANORECTAL SYMPTOMS AND PHYSICAL} EXAMINATION

By definition no faecal masses were palpable in the encopresis/soiling group. In the paediatric constipation groups, however, approximately a third revealed palpable abnormalities. On rectal examination the tone of the internal anal sphincter and voluntary contraction of the external anal sphincter was normal in the two groups. Anal fissures (only one in the paediatric constipation group) and haemorrhoids in the paediatric constipation (three) and encopresis/soiling (two) groups were rarely seen.

\section{TREATMENT}

In the paediatric constipation and encopresis/soiling group 59 and $28 \%$ of the patients respectively used laxative for long periods of time without success. The duration of the laxative treatment, including lactulose, mineral oil, and stimulant laxatives given by mouth or by enema, was 49 months (3-135 months) in children with constipation and 46 months (6-93 months) in the other group. In the paediatric constipation and encopresis/soiling group additional psychiatric treatment was given to $26 \%$ and $18 \%$ respectively. In the encopresis/soiling group most $(62 \%)$ had never received any earlier treatment. In children with paediatric constipation this was only $39 \%$. These nontreated children initially visited a doctor at a significantly older age, median 9 years (6-15 years) in the encopresis/soiling group, compared with 8 years (5-14 years) in the paediatric constipation group. Separation within the paediatric constipation and encopresis/soiling group into those receiving laxative treatment and those who were not treated before did not show any significant difference in the clinical features, except for a significantly higher frequency in large amount of stools (7-30 days) in the untreated paediatric constipation patients.

\section{COLONIC TRANSIT TIME}

Table 2 shows the different segmental and total CTT values. Total CTT was significantly 
higher in the paediatric constipation group compared with the encopresis/soiling group.

In 56 of 111 paediatric constipation patients the total CTT was within the normal limits. ${ }^{26}$ In 22 patients with paediatric constipation with total CTT $>62$ hours a significant delay in transit occurred in the rectosigmoid only, whereas significantly increased transit times in all segments were observed in 14 paediatric constipation patients. In the encopresis/soiling group 44 patients had a total CTT within the normal range. In five encopresis/soiling patients with a total CTT $>62$ hours, the accumulation of markers occurred in the rectosigmoid.

OROCAECAL TRANSIT TIME

The OCTT (median and range) in paediatric constipation, encopresis/soiling, and controls was $60(30-180), 60(30-105)$, and 60 (30-120) minutes respectively. In the paediatric constipation group eight children $(7 \%)$ were classified as non-hydrogen producers, whereas in the encopresis/soiling group only two children $(4 \%)$ had breath hydrogen peaks $<10 \mathrm{ppm}$ above baseline values throughout the three hour test period. All healthy controls were hydrogen producers with breath hydrogen peaks of $>10 \mathrm{ppm}$ above baseline values.

\section{ANORECTAL MANOMETRY}

In 31 paediatric constipation children with extreme faecal retention, disimpaction with enemas was performed daily during the week before manometry to guarantee an empty rectal ampulla and to standardise the anorectal measurements for all patients. No enemas were given on the day of manometric measurements. The remaining patients required no enemas before manometry. Table 3 shows that all manometric parameters were comparable between the two patient groups, apart from a significantly higher threshold of sensation $(p=0.008)$ in children with paediatric constipation. Maximum anal resting tone was significantly higher in the encopresis/soiling group ( $p=0.04)$ than controls. Only the paediatric constipation group required significantly larger balloon volumes to provoke a rectal sensation $(p=0.02)$ compared with healthy controls. In encopresis/soiling patients this threshold was even lower than in controls. Significant higher balloon volumes were needed in the two patient groups compared with control children $(p=0.02$ and $p=0.02$ respectively) in eliciting the rectoanal inhibitory response. The defecation dynamics were abnormal in $59 \%$ and $46 \%$ in the paediatric constipation and encopresis/soiling groups respectively and were significantly different from controls $(p<0 \cdot 001)$. All children exhibited a rectoanal inhibitory reflex on balloon distension.

\section{SUBDIVISION OF PATIENTS}

Subdivision of the constipated group of children (paediatric constipation) into those with and without faecal incontinence and subsequent comparison with the encopresis/ soiling group yielded no differences in the above mentioned clinical features, transit times, and manometric results, as presented in tables 1-3. Similarly, no significant difference was found between those children with paediatric constipation with faecal incontinence and those without faecal incontinence. These findings allow the separation into only two groups.

\section{CHILD BEHAVIOUR CHECKLIST}

On the CBCL, children with paediatric constipation and encopresis/soiling showed high percentages $(38 \cdot 5 \%$ and $44 \cdot 2 \%$ respectively) in the clinical range of behavioural problems, but no significant difference was found between the two groups. In the two groups these scores for behavioural problems differed significantly $(\mathrm{p}<0.01)$ compared with the $10 \%$ abnormal clinical range found in control children.

\section{Discussion}

It is generally believed that encopresis is secondary to constipation; Levine, in particular, suggested this association. ${ }^{1}$ A pilot study, however, implied the existence of a group of children with encopresis without evidence of constipation. ${ }^{29}$ In this study we show that such children form a distinct group among patients with defecation disorders, with discrete clinical and manometric features and normal CTT. In these children solitary encopresis is the most important clinical sign.

Most parents of these children, especially in those with primary encopresis, postponed an initial visit to a doctor for many years, despite the humiliation. Many parents were unaware of the existence of encopresis as a common childhood problem and ascribed it to laziness, inattention, poor hygiene, or stress; shame and cultural taboos were other common reasons for this delay. In contrast, infrequent defecation appeared to be a more threatening and more recognisable disorder and therefore parents of children with paediatric constipation consulted a doctor earlier.

Levine has provided an age dependent list of potential risk factors for encopresis, based on constitutional predispositions, circumstances, of environment, and critical life events. ${ }^{1}$ Nevertheless, only in a minority of patients in this study could these factors be identified. In most children the cause of constipation or encopresis, or both, was unknown. More importantly, and in contrast with general opinion, encopresis or soiling alone was not often associated with too coercive and too early bowel training as these children were less and later toilet trained than the paediatric constipation group. It is possible that changed cultural opinions and behaviour about bowel training explains the differences between our findings and the previous studies.

In children with constipation, the retention of stools often leads to a vicious circle 
in which the rectum is increasingly distended by abnormally firm faecal contents. ${ }^{1}$ The infrequent passage of these hard and large amounts of stools induces pain during defecation, inhibition of voluntary efforts, and results in abnormal sphincter contraction during defecation. Finally, chronic rectal distension causes soiling, sometimes encopresis, loss of rectal sensitivity, and hence a normal urge to defecate. ${ }^{20} 3536$ Levine stated that in most children with faecal incontinence a plain radiograph of the abdomen would unmask extensive faecal retention. ${ }^{1}$ This study shows that a third of the children referred for faecal incontinence showed no signs of constipation. Almost all encopresis/soiling children defecated daily, resulting in significantly fewer constipation associated complaints - for example, abdominal pain and poor appetite. Importantly, and in contrast with children with paediatric constipation, encopresis/soiling patients exhibited no abnormalities on abdominal and rectal examination. Furthermore, no aberrations were found on radiographic examination in most encopresis/ soiling patients using Barr scores, suggesting that children with encopresis/soiling form a distinct group of patients. ${ }^{37}$

The existence of night time soiling, the loss of loose stools in pyjamas, was significantly higher in the paediatric constipation group than in children with encopresis/soiling. In nearly all instances this was correlated with severe faecal impaction and extreme prolonged total CTT (>100 hours). ${ }^{38}$ In encopresis/ soiling children this correlation was not observed.

Preliminary treatment analysis showed that children with paediatric constipation were often helped by laxative treatment, whereas, in contrast, children with encopresis/soiling were seldom helped, and even became worse. Review of published work showed that various approaches have been recommended for the management of children with encopresis. Among these have been individual and family psychotherapy, behaviour modification programs and bowel retaining regimens. ${ }^{39-42}$ Most published studies were either single case reports or consist of small groups of children with encopresis/soiling. ${ }^{43}$ Nolan et al showed in children with encopresis and evidence of accumulated stool on plain abdominal radiograph, an obvious additional advantage of laxative drugs and behaviour modification to behavioural modification alone. ${ }^{44}$ Previously, we showed in a nonrandomised study that children with encopresis and soiling alone were significantly improved after biofeedback training. ${ }^{29}$

The use of radio-opaque markers is important to objectify reports of constipation and or faecal incontinence, which does not depend on possible inaccurate recall. ${ }^{45-47}$ Using the Metcalf method an important difference was found between the two groups. ${ }^{25}$ Total as well as segmental CTT was significantly prolonged in children with paediatric constipation compared with those with encopresis/soiling. This confirms that children with encopresis/soiling have normal bowel movements daily. It is unclear whether children with rapid colonic transit and solitary encopresis without other symptoms of constipation may be helped by suppression of intestinal motility rather than laxative treatment. Interestingly, colonic inertia, slowing of markers through all colonic segments, was only found in paediatric constipation children. ${ }^{48} 49$

No significant differences were found in OCTT in all children studied, suggesting no aetiological role of the small bowel in constipation or encopresis, or both, as described previously. ${ }^{50}$

Studies of anal sphincter pressures in constipated children with or without faecal incontinence have been contradictory; maximum anal resting tone has found to be increased, decreased, or not different from controls. ${ }^{21} 2251-53$ The hypertonicity of the anal canal, as found in the encopresis/soiling group only, is upexplained. Arhan et al suggested that hypertonicity of the anal canal could lead to outlet obstruction. ${ }^{17}$ In the encopresis/soiling group, however, no such correlation could be found when rectosigmoid transit time and maximum anal resting tone were analysed. Similarly, no such correlation could be found in patients with paediatric constipation, despite a significant slowing of markers in the rectosigmoid in this group. Therefore it seems unlikely that anal resting tone is an important factor in the pathophysiology of outlet obstruction in children with constipation or faecal incontinence, or both.

The threshold of sensation in children with paediatric constipation was significantly higher than in controls and, as stated before, most likely the result of faecal impaction. ${ }^{19-2154}$ Surprisingly, the balloon volume needed to provoke rectal sensation in children with encopresis/soiling was even lower than in controls, suggesting that patients with encopresis/soiling are able to perceive normal rectoanal stimuli. Furthermore, none of these children had faecal impaction on rectal examination and most showed normal total CTT on marker studies. In most of those with encopresis/soiling 'accidents' happened after $3.00 \mathrm{pm}$, whereas in paediatric constipation children lost faeces any time during the day. Children with encopresis/soiling commonly trace the failure to 'no time to go to the toilet' or, 'I could not leave my computer game', or 'I did sense the urge, but I was just too late', suggesting that these children deny or neglect their normal and appropriate physiological stimuli. Interestingly, many children with encopresis/soiling initially stated an absence of any sense or urge to defecate.

In the two groups a high percentage of children showed a paradoxal anal response to straining - that is, contraction rather than relaxation of the anal sphincters on defecation attempts. This phenomenon was earlier reported to occur in up to $55 \%$ of children and adults with defecation disorders. ${ }^{22} 2355$ The cause of this pelvic floor dyssynergia is unknown. In children with paediatric constipation it is suggested that the pain related to 
the defecation of large, firm stools may result in unconscious contraction of sphincters to avert or stop pain during defecation. 2256 Encopresis/soiling patients had, however, except for two children, no history of constipation and none reported the periodic passage of large amounts of stools. They had significantly less pain during defecation and significantly more normal stools than children with paediatric constipation, suggesting that anal pain is not the only reason for abnormal expulsion patterns. In addition, within the encopresis/soiling group, rectosigmoid transit time did not differ among the children with normal or abnormal defecation dynamics, whereas in children with paediatric constipation, abnormal defecation dynamics were significantly associated with slowing of markers in the rectosigmoid $(p=0.03)$ compared with those children with paediatric constipation who had normal dynamics (data not shown). Loening Baucke showed a decrease in rectosigmoid motility in chronically constipated children. ${ }^{57}$ Thus, in patients with paediatric constipation abnormal defecation dynamics are related to the slowing of rectosigmoid transit time and decreased rectosigmoid motility. In contrast, abnormal defecation dynamics in children with encopresis/soiling did not result in prolonged rectosigmoid or total CTT, nor did it lead to abnormal defecation frequencies. This suggests that these children, despite a pathological defecation technique, are able to produce complete or nearly complete bowels. As mentioned above, children with encopresis/soiling often begrudge the time necessary to visit the toilet and consequently lose some of their bowel contents during play. We suggest that after they sense the urge to defecate they let go their first stools and subsequently contract their voluntary sphincter muscles firmly. By doing this daily, they unconsciously develop abnormal defecation dynamics.

On the CBCL we observed that children with paediatric constipation and encopresis/soiling had a significantly higher incidence of behaviour problems than a normative sample of non-referred Dutch children. Loening Baucke et $a l^{58}$ and Wald et al ${ }^{22}$ showed similar high percentages for behaviour problems in children with constipation and encopresis in $50 \%$ and $45 \%$ respectively. Currently a prospective study is being conducted, using the CBCL before and after treatment, to analyse whether constipation or encopresis, or both, leads to behavioural problems or vice versa.

This study illustrates the importance of the interpretation of clinical symptoms, the use of marker studies, and the value of anorectal manometry in children with defecation disorders. Not all children will present with infrequent painful defecation associated with abdominal pain and poor appetite. This study indicates that children reporting encopresis with normal defecation frequencies, without associated symptoms of constipation, with normal CTTs and normal threshold of anal sensation probably form a distinct entity among children with defecation disorders. In our, as yet, limited experience these children respond favourably to behavioural treatments such as biofeedback training.

We are grateful to G W Akkerhuis of the department of child psychiatry for analysis of the child behaviour checklist.

1 Levine MD. Encopresis: its potentiation, evaluation, and alleviation. Pediatr Clin North Am 1982; 29: 315-30.

2 Kisch EH, Pfeffer CR. Functional encopresis: psychiatric inpatient treatment. Am 7 Psychother 1984; 38: 264-71.

3 Landman GB, Rappaport L, Fenton T, Levine M. Locus of control and self-esteem in children with encopresis. foumal of Developmental and Behavioral Pediatrics 1986; 7 : $111-3$.

4 Weissenberg S. Uber Enkopresis. Z Kinderheilkd 1926; 40: 674 .

5 Bellman M. Studies on encopresis. Acta Paediatr Scand Suppl 1966; 170: 1-50.

6 Clavden GS. Constipation and soiling in childhood. BMF 1976 ; i: $515-7$.

7 Garrard SD, Richmond JB. Psychogenic megacolon manifested by faecal soiling. Pediatrics $1954 ; 10: 474-81$.

8 Pinkerton P. Psychogenic megacolon in children: the implications of bowel negativism. Arch Dis Child 1958; 33: $371-80$

9 Anthony EJ. An experimental approach to the psychopathology of childhood encopresis. Br 7 Med Psycho 1957; 30: 146

10 Boon FL, Singh NN. A model for the treatment of encopresis. Behaviour Modification 1991; 15: 355-71.

11 Olatawura MO. Encopresis: a review of thirty-two cases. Acta Paediatr Scand 1973; 62: 358-64.

12 Mercer RD. Constipation. Pediatr Clin North Am 1967; 14: 175.

13 Levine MD. Children with encopresis: a descriptive analysis. Pediatrics 1975 ; 56: 412-6.

14 National Child Development Survey. From birth to seven. London: National Child Development Survey, 1972 399

15 Wolters WHG. Encopresis: een psychosomatische benadering [Thesis]. Utrecht: University of Utrecht, 1974.

16 Loening Baucke VA, Younoszai MK. Abnormal anal sphincter response in chronically constipated children f Pediatr 1982; 100: 213-8

17 Arhan P, Devroede G, Jehannin B, et al. Idiopathic disorders of faecal continence in children. Pediatrics 1983; 71 : $774-9$.

18 Corazziari E, Cucchiara S, Staiano A, et al. Gastrointestinal transit time, frequency of defecation, and anorectal manometry in healthy and constipated children. $\mathcal{F}$ Pediat 1985; 106: 379-82.

19 Cucchiara S, Coremans G, Staiano A, et al. Gastrointestinal transit time and anorectal manometry in children with faecal soiling. I Pediatr Gastroenterol Nutr 1984; 3: 545-50.

20 Meunier P, Mollard P, Marechal JM. Physiopathology of megarectum: the association of megarectum with encopresis. Gut 1976; 17: 224-7.

21 Molnar D, Taitz IS, Urwin OM, Wales JKH. Anorectal manometry results in defecation disorders. Arch Dis Child manometry results

22 Wald A, Chandra R, Chiponis D, Gabel S. Anorectal function and continence mechanisms in childhood encopresis. Pediatr Gastroenterol Nutr 1986; 5: 346-51.

23 Loeining Baucke VA, Cruikshank BM. Abnormal defecation dynamics in chronically constipated children with encopresis. F Pediatr 1986; 108: 562-6.

24 Gilat T, Ben Hur H, Gelman-Malachi E, Teriman R, Peled Y. Alterations of the colonic flora and their effect on the hydrogen breath test. Gut 1978; 19: 602-5.

25 Metcalf AM, Phillips SF, Zinsmeister AR, MacCarty RL, Beart RW, Wolff BG. Simplified assessment of segmental Beart RW, Wolff BG. Simplified assessment of

26 Arhan P, Devroede G, Jehannin B, et al. Segmental colonic transit time. Dis Colon Rectum 1981; 24: 625-9.

27 van der Kley-van Moorsel JM, Douwes AC, van Oeveren JP. New principle for estimation of hydrogen in expired air. Eur F Pediatr 1984; 141: 221-4

28 Metz G, Gassull MA, Leeds AR, Blendis LM, Jenkins DJA. A simple method of measuring breath hydrogen in carbohydrate malabsorption by end-expiratory sampling. Clin Sci Molec Med 1975; 85: 546-55.

29 Benninga MA, Büller HA, Taminiau JAJM. Biofeedback training in chronic constipation. Arch Dis Child 1993; 68: $126-9$

30 Arndorfer RC, Steff JJ, Dodds WJ. Linehan JH, Hogan WJ Improved infusion system for intraluminal esophageal manometry. Gastroenterology 1977; 73: 23-7.

31 Loening Baucke VA. Anuras S. Anorectal manometry in healthy elderly subjects. $f$ Am Geriatr Soc 1984; 32: 636-9.

32 Buser WD, Miner Jr PB. Delayed rectal sensation with faecal incontinence. Gastroenterology 1986; 91: 1186-91.

33 Achenbach TM, Edelbrock C. Manual for the child behaviour checklist and revised child behaviour profile. Burlington: University of Vermont, 1983.

34 Verhulst FC. Mental health in Dutch children [Thesis]. Meppel: Krips repro, 1985.

35 Loening Baucke VA. Sensitivity of the sigmoid colon and rectum in children treated for chronic constipation. f Pediatr Gastroenterol Nutr 1984; 3: 454-9. 
36 Davidson $\mathrm{M}$, Kugler MM, Bauer $\mathrm{CH}$. Diagnosis and management in children with severe and protracted constipation and obstipation. $\mathcal{F}$ Pediatr 1963; 62: 261-75.

37 Barr RG, Levine MD, Wilkinson RH, Mulihill D. Occult stool retention: a clinical tool for its evaluation in schoolaged children. Clin Pediatr (Phila) 1979; 18: 674-9.

38 Benninga MA, Büller HA, Akkermans LM, Taminiau JA. Does slow transit constipation exist in children? Gastroenterology 1993; 104: A475.

39 Easson WM. Encopresis-psychogenic soiling. Can Med Assoc 7 1960; 82: 624

40 Keilbach $\mathrm{H}$. Untersuchung an acht kindern mit der hauptsymptomatik einkoten. Prax Kinderpsychol 1977; 4: symptom

41 Seymour FW. The treatment of encopresis using behaviour modification. Australian Paediatric fournal 1976; 12: 326-9.

42 Ashkenazy $Z$. Treatment of encopresis using a discriminative stimulus. F Behav Ther Exp Psychiatry 1975; 6: 155-7.

43 Parker L, Whitehead WE. Treatment of urinary and fecal incontinence in children. In: Russo DR, Varni JW, eds. Behavioural pediatrics: research and practice. New York: Plenum Press, 1982: 143-74.

44 Nolan T, Debelle G, Oberklaid F, Coffey C. Randomised trial of laxatives in treatment of childhood encopresis. Lancet 1991; 338: 523-7.

45 Hinton JM, Lennard-Jones JE, Young AC. A new method for studying gut transit times using radiopaque markers. Gut 1969; 10: 842-7.

46 Whitehead WE, Chaussade S, Corazziari E, Kumar D. Report of an international workshop on management of constipation. Gastroenterology Int 1991; 4: 99-113.

47 Wald A, Hinds JP, Caruana J. Psychological and physiological characteristics of patients with severe idiopathic constipation. Gastroenterology 1989; 97: 932-7.
48 Preston DM, Lennard-Jones JE. Severe chronic constipation of young women: 'idiopathic slow transit constipation'.

49 Wald A. Colonic transit and anorectal manometry in chronic idiopathic constipation. Arch Intern Med 1986; 146: 1713-6.

50 Vajro P, Silano G, Longo D, Staiano A, Fontanella A. Orocaecal transit time in healthy and constipated children. Acta Paediatr Scand 1988; 77: 583-6.

51 Martelli H, Devroede G, Arhan P, Dunguay C. Mechanisms of idiopathic constipation: outlet obstruction. Gastroenterology 1978; 75: 623-31.

52 Meunier P, Marechal JM, de Beaujeu J. Rectoanal pressures and rectal sensitivity studies in chronic childhood constipation. Gastroenterology 1979; 77: 330-6.

53 Loening Baucke VA, Younoszai MK. Effect of treatment on rectal and sigmoid motility in chronically constipated children. Pediatrics 1984; 73: 199-205.

54 Loening Baucke VA. Factors determining outcome in children with chronic constipation and faecal soiling. Gut 1989; 30: 999-1006.

55 Lestar B, Penninckx FM, Kerremans RP. Defaecometry: a new method for determining the parameters of rectal new method for determining the parameters of

56 Keren S, Wagner Y, Heldenberg D, Golan M. Studies of manometric abnormalities of the rectoanal region during defecation in constipated and soiling children: modification through biofeedback therapy. Am $\mathcal{f}$ Gastroenterol 1988; 83: 827-31.

57 Loening Baucke VA. Abnormal rectoanal function in children recovered from chronic constipation and encopresis. Gastroenterology 1984; 87: 1299-304.

58 Loening Baucke VA, Cruikshank B, Savage C. Defecation and behaviour profiles in encopretic children. Pediatrics 1987; 80: 672-9. 